\title{
Desempenho bioeconômico de suínos em crescimento e terminação alimentados com rações contendo farelo de coco'
}

\section{José Evânio da Costa Siebra², Maria do Carmo Mohaupt Marques Ludke ${ }^{3}$, Jorge Vitor Ludke $^{4}$, Teresinha Marisa Bertol ${ }^{4}$, Wilson Moreira Dutra Júnior ${ }^{3}$}

\author{
1 Projeto financiado pela EAFS-PB \\ 2 Escola Agrotécnica Federal de Souza, Souza-PE. \\ 3 Universidade Federal Rural de Pernambuco, UFRPE - Depto de Zootecnia s/n, Bairro Dois Irmãos, Recife, PE, CEP: $52.171-900$. \\ 4 Embrapa Suínos e Aves.
}

RESUMO - Objetivou-se avaliar o desempenho de suínos em crescimento e terminação alimentados com rações contendo farelo de coco. Foram utilizados 20 suínos machos castrados mestiços Landrace $\times$ Large White com 19,7 $\pm 2,9$ kg de peso vivo inicial e $89,2 \pm 5,8 \mathrm{~kg}$ de peso vivo final distribuídos em delineamento de blocos casualizados com quatro tratamentos (0, 10 , 20 ou $30 \%$ de farelo de coco) e cinco repetições. Avaliaram-se o desempenho, o ganho de peso médio diário, o consumo de ração médio diário e a conversão alimentar nas fases de crescimento (65 a 107 dias de idade) e crescimento-terminação (65 a 149 dias de idade). Os parâmetros econômicos avaliados foram a receita bruta média, o custo médio da alimentação, a margem bruta média e a rentabilidade média. Os melhores resultados de ganho de peso médio diário e receita bruta média na fase de crescimento foram obtidos com o nível de $22,5 \%$ de farelo de coco na ração. $\mathrm{Na}$ fase de crescimento-terminação, a receita bruta média no período total indica que é possível incluir $22,4 \%$ de farelo de coco em dietas para suínos formuladas com farelo residual de milho e farelo de soja.

Palavras-chave: alimento alternativo, farelo residual de milho, nutrição de suínos

\section{Bioeconomic performance of growing - finishing pigs fed diet with coconut meal}

\begin{abstract}
The objective was to evaluate the performance of growing- finishing pigs fed diet with coconut meal. Twenty crossbred Large White $\times$ Landrace barrows with initial $19.7 \pm 2.9 \mathrm{~kg} \mathrm{BW}$ and final $89.2 \pm 5.8 \mathrm{~kg} \mathrm{BW}$ were allotted to complete a randomized blocks design with four levels $(0,10,20$ or 30\%) of coconut meal and five replications. Performance traits, as average daily weight gain, average daily feed intake and feed conversion ratio in grower phase (65 to 107 days old) and grower-finisher phase (65 to 149 days old) were evaluated. Economic parameters evaluated were: average gross income, average feed cost, gross margin and average return. The best results of average weight daily gain and average gross income in the grower phase were obtained with the level of $22.5 \%$ of coconut meal in the diet. In grower-finisher phase, the average gross income in total period indicates that it is possible to include $22.4 \%$ of coconut meal in diets for pigs raised with residual corn meal and soybean meal.
\end{abstract}

Key Words: alternative feed, nutrition of pigs, residual corn meal

\section{Introdução}

A necessidade de utilização de ingredientes alternativos em dietas para suínos em crescimento e terminação, com o objetivo de reduzir custos de produção, é constante na suinocultura (Andrade, 2001).

O coqueiro (Cocos nucifera L.) é originário do sudeste asiático e é cultivado em grande parte das ilhas e regiões litorâneas tropicais. No Brasil, as maiores plantações concentram-se nas regiões costeiras dos estados do Nordeste em área estimada de 200 mil hectares. A Bahia é, atualmente, o maior produtor brasileiro seguido pelo Ceará, Sergipe e Alagoas. Nas condições de industrialização do coco no Brasil o rendimento médio de farelo é de 16 toneladas por hectare ao ano (FIBGE, 2006).

O farelo de coco, por não apresentar fator antinutricional, é considerado ingrediente energético, mas apresenta 10 a $12 \%$ de fibra bruta, que influencia o aproveitamento dos nutrientes. $O$ farelo, além de sua característica energética, possui elevado teor de proteína bruta, que varia de 20 a $25 \%$, e, dessa forma, torna-se um ingrediente com dupla função e que substitui as fontes energéticas e protéicas. 
Apesar do teor de proteína bruta, o farelo de coco apresenta perfil de aminoácidos diferente do encontrado no farelo de soja. O calor excessivo durante o processamento indisponibiliza de forma acentuada a lisina por meio da complexação com açúcares livres, reduzindo a qualidade da proteína (Woodroof, 1970). Altas temperaturas durante a estocagem aceleram a rancificação e, em regiões de grande umidade, a armazenagem em condições inadequadas pode favorecer a contaminação microbiana.

Fialho et al. (1985), em estudos de digestibilidade com suínos, determinaram valores de energia digestível de $3.197 \mathrm{kcal} / \mathrm{kg}$ e de energia metabolizável de $3.096 \mathrm{kcal} / \mathrm{kg}$ para farelo de coco com $92,87 \%$ de matéria seca, $70,93 \%$ de matéria seca digestível e coeficiente de digestibilidade da proteína de $62,13 \%$.

Níveis elevados de farelo de coco resultam em dietas fibrosas e com funções nutricionais que diferem de acordo com a espécie utilizada. Na nutrição de ruminantes, a fibra dietética é fundamental, ao passo que, na nutrição de não-ruminantes, como os suínos, o valor desse componente dietético depende da capacidade fermentativa do intestino grosso desses animais (Kass et al., 1980b). A utilização da fibra na alimentação animal é conveniente do ponto de vista econômico e do bem-estar (Anderson \& Lindberg, 1997), mas tem efeitos negativos sobre a digestibilidade dos nutrientes e da energia (Noblet \& Perez, 1993)

Lekule et al. (1982) avaliaram dietas contendo 0, 10, 20 e $30 \%$ de farelo de coco para suínos até o peso de abate de $90 \mathrm{~kg}$ e observaram que a taxa e a eficiência de ganho reduziram nos níveis superiores a $10 \%$ de farelo. Os suínos foram alimentados com quantidades restritas de ração e aqueles que receberam as rações com 20 e $30 \%$ de farelo de coco não consumiram todo o alimento.

Este trabalho foi realizado com o objetivo de caracterizar o desempenho animal e analisar a viabilidade econômica da utilização de farelo de coco (Cocos nucifera $L$ ) como alimento alternativo para suínos em crescimento e crescimento-terminação.

\section{Material e Métodos}

O experimento foi realizado na Unidade Educativa de Produção de Suinocultura da Escola Agrotécnica Federal de Sousa (EAFS), em Sousa, Paraíba, durante o período de 21 de junho a 13 de setembro de 2005. A cidade está localizada a $220 \mathrm{~m}$ de altitude, $6^{\circ} 45^{\prime} 33^{\prime \prime}$ de latitude sul e $38^{\circ}$ $13^{\prime} 41^{\prime \prime}$ de longitude oeste, com temperatura média anual de $27^{\circ} \mathrm{C}$ e $58 \%$ de umidade relativa do ar, na região do alto sertão da Paraíba, a 444 km de João Pessoa.
Foram utilizados 20 animais do rebanho da Escola Agrotécnica, machos castrados mestiços (Landrace $\times$ Large White), com peso médio inicial de 19,7 $\pm 2,9 \mathrm{~kg}$. Os animais foram alojados individualmente em 20 baias de alvenaria medindo $1,50 \times 2,15 \mathrm{~m}$, dotadas de comedouros tipo cocho com $6 \mathrm{~cm}$ de altura, $10,5 \mathrm{~cm}$ de largura e $3,5 \mathrm{~cm}$ de profundidade e bebedouros tipo chupeta localizados na parede oposta aos comedouros.

Os animais foram distribuídos em blocos casualizados por peso inicial e grau de parentesco, com cinco repetições e um animal por unidade experimental. As dietas foram formuladas com $0,10,20$ ou $30 \%$ de farelo de coco, de modo a atender às exigências nutricionais para animais de médio potencial genético, conforme recomendações de Rostagno et al. (2000): todas isoprotéicas, com 18,6 e $15,2 \%$ de $\mathrm{PB}$, isoenergéticas, $3.265 \mathrm{kcal} / \mathrm{kg}$, e isolisínicas, 0,85 e $0,72 \%$, respectivamente, para as fases de crescimento e terminação.

O farelo foi adquirido de indústria de óleo e torta de coco da cidade de Sousa, Paraíba, todo de uma só vez. A indústria realiza a extração de óleo de coco por prensagem a quente. Foram realizadas análises bromatológicas dos ingredientes (Tabela 1) e das rações (Tabela 2) utilizadas nas fases de crescimento e terminação no Laboratório de Nutrição Animal do Departamento de Zootecnia da Universidade Federal Rural de Pernambuco (UFRPE), onde foram determinados os teores de proteína bruta (PB), fibra bruta (FB), extrato etéreo (EE) e fósforo total.

Para o estudo dos efeitos dos níveis de farelo de coco sobre o desempenho, foram avaliados o ganho de peso médio diário (GPMD, g/dia), o consumo de ração médio diário (CRMD, g/dia) e a conversão alimentar (CA, g/g) nas fases de crescimento (65 a 107 dias de idade) e crescimentoterminação (de 65 a 149 dias de idade). Como parâmetros econômicos, avaliaram-se a receita bruta média (peso do suíno vivo $\times$ preço pago por kg do suíno), o custo médio da alimentação (consumo de ração $\times$ preço unitário da ração), a margem bruta média (diferença entre receita bruta média e custo médio da alimentação) e a rentabilidade média (margem bruta/custo da alimentação), conforme descrito por Lanna (2000).

A avaliação econômica refere-se ao custo parcial de produção das dietas com farelo de coco, considerando os preços médios regionais dos ingredientes das rações e o preço por quilograma de suíno vivo. As pesagens dos animais foram realizadas em intervalos de 7 dias, sempre às $6 \mathrm{~h}$. Água e rações foram fornecidas à vontade durante todo o experimento. A ração foi fornecida uma vez ao dia, no período da manhã. 
O fornecimento foi à vontade, porém controlado, de modo que a mínima oferta diária de ração em cada unidade experimental fosse proporcional ao peso metabólico do animal $\left(\mathrm{PV}^{0,75}\right)$ considerando a concentração de energia metabolizável da dieta. Ao adotar o fornecimento diário de quatro vezes a exigência de mantença, foi possível assegurar pleno arraçoamento. Antes do fornecimento da ração, diariamente as sobras e os desperdícios foram recolhidos e pesados com a finalidade de corrigir o consumo diário. Dessa forma, quando não havia sobras, aumentava-se a quantidade oferecida anteriormente.

O delineamento experimental utilizado foi o de blocos casualizados conforme o modelo matemático: $\mathrm{Y}_{\mathrm{ij}}=\mu+\mathrm{t}_{\mathrm{i}}+$ $b_{j}+e_{i j}$, em que: $Y_{i j}=$ valor observado na parcela sob o tratamento $\mathrm{i}$ e encontrado no bloco $\mathrm{j} ; \mu=$ média da população; $t_{i}=$ efeito do tratamento $i$ aplicado na parcela; $b_{j}=$ efeito do bloco $j$, em que se encontra a parcela; e $\mathrm{e}_{\mathrm{ij}}=$ efeito dos fatores não controlados na parcela.

Os parâmetros de desempenho e os resultados econômicos associados nas fases de crescimento e de crescimento e terminação foram submetidos à análise de variância e regressão utilizando-se o programa computacional Statistical Analysis System (SAS, 1999). Adicionalmente, visando maior informação, sempre que foi verificado nível de significância para o efeito de tratamentos, as médias dos parâmetros foram avaliadas pelo teste Tukey a $5 \%$ de probabilidade.

\section{Resultados e Discussão}

No local de realização do experimento de desempenho, foram observadas as seguintes médias de temperatura: média geral de $28,7^{\circ} \mathrm{C}$, média mínima de $22^{\circ} \mathrm{C}$ e média máxima de $31,7^{\circ} \mathrm{C}$. Os resultados da análise laboratorial do farelo de coco usado no experimento indicaram alto teor de gordura residual em comparação aos valores atualmente expressos nas tabelas de composição de alimentos, fato relacionado ao nível tecnológico utilizado na indústria.

Como foram utilizados quatro níveis de farelo de coco e houve efeito cúbico para alguns dos parâmetros avaliados, a apresentação dos resultados de análise de variância e de regressão foi acompanhada do teste Tukey para as médias.

Os resultados da análise de regressão indicaram efeito cúbico $(\mathrm{p}<0,01)$, na fase de crescimento, dos níveis de farelo de coco sobre o consumo e o ganho de peso, porém, no período total, não foram observadas diferenças significativas ( $p>0,05)$ nessas características de desempenho. Na análise de regressão, também não foi observada significância para a conversão alimentar na fase de crescimento e no período total.

Os maiores valores de consumo e ganho de peso foram observados com a inclusão de $20 \%$ de farelo de coco na fase de crescimento. Esse nível promoveu aumento de $21,5 \%$ no consumo e de $32,6 \%$ no ganho de peso, mas não influenciou a conversão alimentar.

Tabela 1 - Composição nutricional dos farelos residual de milho, soja e coco utilizados no experimento de desempenho

\begin{tabular}{|c|c|c|c|}
\hline Nutriente $(\%)$ & Farelo residual de milho ${ }^{3}$ & Farelo de soja & Farelo de coco \\
\hline \multicolumn{4}{|l|}{ Parâmetro analisado ${ }^{1}$} \\
\hline Proteína bruta & 12,47 & 45,50 & 20,39 \\
\hline Gordura bruta & 11,04 & 1,38 & 9,79 \\
\hline Fibra bruta & 13,25 & 5,92 & 10,67 \\
\hline Fósforo total & 0,50 & 0,59 & 0,50 \\
\hline \multicolumn{4}{|l|}{ Valores tabelados ${ }^{2}$} \\
\hline Fibra detergente neutro & 43,69 & 13,29 & 47,88 \\
\hline Fibra detergente ácido & 14,08 & 9,39 & 21,58 \\
\hline Fósforo disponível & 0,17 & 0,19 & 0,17 \\
\hline Cálcio & 0,04 & 0,32 & 0,12 \\
\hline Lisina & 0,55 & 2,78 & 0,59 \\
\hline Metionina+cistina & 0,45 & 1,27 & 0,53 \\
\hline Triptofano & 0,06 & 0,65 & 0,20 \\
\hline Arginina & 0,73 & 3,33 & 2,40 \\
\hline Fenilalanina & 0,87 & 3,79 & 1,36 \\
\hline Isoleucina & 0,39 & 2,11 & 0,63 \\
\hline Coeficiente de digestibilidade da proteína bruta, \% & 50,0 & 90,0 & 67,3 \\
\hline Energia metabolizável aparente, $\mathrm{kcal} / \mathrm{kg}$ & 3.210 & 3.138 & 3.185 \\
\hline
\end{tabular}

1 Valores analisados no Laboratório de Nutrição Animal do Departamento de Zootecnia da Universidade Federal Rural de Pernambuco (UFRPE).

2 Valores de Novus (1994).

${ }^{3}$ Farelo residual de milho: mistura composta de casca, gérmen e amido de grãos de milho (Zea mays), resultante do processamento a seco para obtenção de farinha de milho de mesa destinada ao consumo humano. 
Tabela 2 - Composição e custos totais das rações utilizadas nas fases de crescimento e terminação

\begin{tabular}{|c|c|c|c|c|c|c|c|c|}
\hline \multirow[t]{3}{*}{ Ingrediente } & \multicolumn{8}{|c|}{ Nível de inclusão de farelo de coco (\%) } \\
\hline & \multicolumn{4}{|c|}{ Crescimento } & \multicolumn{4}{|c|}{ Terminação } \\
\hline & 0 & 10 & 20 & 30 & 0 & 10 & 20 & 30 \\
\hline Óleo de soja & 2,55 & 2,55 & 2,55 & 2,55 & 2,24 & 2,24 & 2,24 & 2,24 \\
\hline Farelo de coco & 0,00 & 10,00 & 20,00 & 30,00 & 0,00 & 10,00 & 20,00 & 30,00 \\
\hline Farelo residual de milho & 75,28 & 67,58 & 59,87 & 52,17 & 86,15 & 78,44 & 70,74 & 63,04 \\
\hline Farelo de soja & 20,23 & 17,86 & 15,50 & 13,13 & 9,79 & 7,42 & 5,06 & 2,69 \\
\hline Calcário calcítico & 1,18 & 1,17 & 1,17 & 1,16 & 1,04 & 1,04 & 1,03 & 1,02 \\
\hline Fosfato bicálcico & 0,34 & 0,35 & 0,35 & 0,36 & 0,24 & 0,25 & 0,25 & 0,26 \\
\hline Sal comum & 0,16 & 0,16 & 0,16 & 0,16 & 0,17 & 0,17 & 0,17 & 0,17 \\
\hline L-lisina $\mathrm{HCl}$ & 0,11 & 0,18 & 0,25 & 0,32 & 0,22 & 0,29 & 0,36 & 0,43 \\
\hline Premix vitamínico 1,2 & 0,10 & 0,10 & 0,10 & 0,10 & 0,10 & 0,10 & 0,10 & 0,10 \\
\hline Premix mineral 3,4 & 0,05 & 0,05 & 0,05 & 0,05 & 0,05 & 0,05 & 0,05 & 0,05 \\
\hline Composição calculada $^{5}(\%)$ & 100,00 & 100,00 & 100,00 & 100,00 & 100,00 & 100,00 & 100,00 & 100,00 \\
\hline Energia metabolizável ( $\mathrm{kcal} / \mathrm{kg})$ & 3.265 & 3.265 & 3.265 & 3.265 & 3.265 & 3.265 & 3.265 & 3.265 \\
\hline Proteína bruta & 18,60 & 18,60 & 18,60 & 18,60 & 15,20 & 15,20 & 15,20 & 15,20 \\
\hline Gordura bruta & 11,1 & 11,1 & 11,2 & 11,3 & 11,9 & 12,0 & 12,1 & 12,2 \\
\hline Fibra bruta & 11,2 & 11,1 & 11,0 & 10,9 & 12,0 & 11,9 & 11,8 & 11,7 \\
\hline Fibra detergente neutro & 35,6 & 36,7 & 37,8 & 38,9 & 38,9 & 40,0 & 41,1 & 42,2 \\
\hline Fibra detergente ácido & 12,4 & 13,3 & 14,2 & 15,1 & 13,0 & 13,9 & 14,8 & 15,7 \\
\hline Cálcio & 0,60 & 0,60 & 0,60 & 0,60 & 0,50 & 0,50 & 0,50 & 0,50 \\
\hline Fósforo total & 0,56 & 0,56 & 0,56 & 0,56 & 0,51 & 0,51 & 0,51 & 0,51 \\
\hline Fósforo disponível & 0,23 & 0,23 & 0,23 & 0,23 & 0,21 & 0,21 & 0,21 & 0,21 \\
\hline Lisina digestível & 0,85 & 0,85 & 0,85 & 0,85 & 0,72 & 0,72 & 0,72 & 0,72 \\
\hline Metionina+cistina digestível & 0,49 & 0,47 & 0,46 & 0,44 & 0,42 & 0,41 & 0,40 & 0,40 \\
\hline Treonina digestível & 0,50 & 0,48 & 0,46 & 0,44 & 0,35 & 0,33 & 0,31 & 0,29 \\
\hline Preço/100 kg de ração (R\$) & 64,19 & 62,24 & 60,38 & 58,45 & 59,78 & 57,96 & 56,01 & 53,68 \\
\hline
\end{tabular}

${ }^{1}$ Cada quilograma do produto contém: Se - 270 mg; vit. A - 2.880 .000 UI; vit. D3 - 585.000 Ul; vit. E - 12.150 mg; vit. K - 900 mg; vit. B1 - 450 mg; vit. B2 - $2.520 \mathrm{mg}$; vit. B6 - $540 \mathrm{mg}$; vit. B12 - $9.450 \mathrm{mcg}$; ácido fólico - $225 \mathrm{mg}$; ácido pantotênico - $8.400 \mathrm{mg}$; niacina - $14.400 \mathrm{mg}$; aditivo antioxidante - $170 \mathrm{mg}$. ${ }^{3}$ Quilograma do produto contém: $\mathrm{Mn}-27.000 \mathrm{mg} ; \mathrm{Zn}-144.000 \mathrm{mg} ; \mathrm{Fe}-99.000 \mathrm{mg}$; Cu - $14.400 \mathrm{mg} ; \mathrm{I}-540 \mathrm{mg}$.

${ }^{2}$ Quilograma do produto contém: vit. A - 2.520.000 UI; vit. D3 - 540.000 UI; vit. E - 9.900 mg; vit. K3 - 720 mg; vit. B1 - 405 mg; vit. B2 - 1.980 mg; vit. B5 - $405 \mathrm{mg}$; vit. B12 - $8.100 \mathrm{mcg}$; niacina - $12.600 \mathrm{mg}$; ácido fólico - $225 \mathrm{mg}$; ácido pantotênico - $6.300 \mathrm{mg}$; Se - $270 \mathrm{mg}$; aditivo antioxidante - $170 \mathrm{mg}$. 4 Quilograma do produto contém: Mn - $27.000 \mathrm{mg} ; \mathrm{Zn}-144,000 \mathrm{mg} ; \mathrm{Fe}-99,000 \mathrm{mg} ; \mathrm{Cu}-14,400 \mathrm{mg} ; \mathrm{I}-540 \mathrm{mg}$.

5 Composição calculada segundo Rostagno et al. (2000).

As equações de regressão para o consumo de ração e ganho de peso (Figuras 1 e 2) na fase de crescimento indicam dois níveis significativos de farelo de coco: um nível baixo, no qual os valores das médias estimadas para consumo ( $1.599 \mathrm{~g} / \mathrm{dia})$ e ganho de peso $(626 \mathrm{~g} / \mathrm{dia})$ foram mínimos; e outro nível alto, no qual os valores das médias estimadas para consumo ( $2.075 \mathrm{~g} / \mathrm{dia})$ e ganho de peso $(936 \mathrm{~g} /$ dia) foram máximos.

No período total, o efeito do nível de $20 \%$ de farelo de coco proporcionou aumento de $17,7 \%$ no consumo de ração e de $19,3 \%$ no ganho de peso. As alterações na composição da dieta observadas no nível de $20 \%$ de farelo de coco correspondem, respectivamente, a reduções de 15 e $5 \%$ na concentração de farelo residual de milho e farelo de soja.

Entre os principais componentes das dietas, o farelo de soja possui o mais alto grau de digestibilidade da matéria orgânica e da proteína bruta, enquanto o farelo residual de milho apresenta os valores mais baixos de digestibilidade desses nutrientes. Os coeficientes de digestibilidade tabelados para a proteína bruta do farelo de coco, do farelo de soja e do farelo residual de milho são, respectivamente, 67,3;90,0 (Rostagno et al., 2005) e 50,0\% (NOVUS, 1994).

Os melhores resultados de ganho de peso e consumo de ração durante a fase de crescimento obtidos no nível de $20 \%$ de farelo de coco podem ser atribuídos à redução do nível de farelo residual de milho na dieta, o que permitiu maior consumo e ganho de peso dos animais. Silva (1996), utilizando farelo residual de milho de mesma procedência do empregado neste experimento, constatou que a utilização de altos níveis de farelo residual de milho em substituição ao milho ocasionou redução no consumo e ganho de peso em suínos nas fases inicial e de crescimento. O fornecimento de farelo de coco em substituição a parte do farelo residual de milho como fonte de energia e a parte o farelo de soja como fonte protéica apresenta efeitos positivos em comparação ao farelo residual de milho e aspectos negativos em comparação ao uso de farelo de soja, visto que a digestibilidade da proteína bruta no farelo de coco é menor que no farelo de soja (Hong et al., 2003). Assim, na 
Tabela 3 - Consumo médio diário de ração (CMDR, g), ganho de peso médio diário (GPMD, g) e conversão alimentar (CA, g/g) nas fases de crescimento e crescimento-terminação

\begin{tabular}{|c|c|c|c|c|c|c|}
\hline \multirow{2}{*}{$\begin{array}{l}\text { Período experimental } \\
\text { Nível de farelo de coco }(\%)\end{array}$} & \multicolumn{3}{|c|}{ Crescimento } & \multicolumn{3}{|c|}{ Crescimento-terminação } \\
\hline & CMDR & GPMD & $\mathrm{CA}$ & CRMD & GPMD & $\mathrm{CA}$ \\
\hline 0 & $1691 b$ & $694 b$ & $2,449 \mathrm{a}$ & $2060 \mathrm{~b}$ & $770 \mathrm{~b}$ & $2,661 \mathrm{a}$ \\
\hline 10 & $1714 b$ & $695 b$ & $2,465 \mathrm{a}$ & $2145 b$ & $800 \mathrm{~b}$ & $2,674 \mathrm{a}$ \\
\hline 20 & $2055 \mathrm{a}$ & $920 a$ & $2,232 \mathrm{a}$ & $2424 a$ & $919 a$ & $2,635 \mathrm{a}$ \\
\hline 30 & $1728 b$ & $729 b$ & $2,379 a$ & $2167 b$ & $823 b$ & $2,637 \mathrm{a}$ \\
\hline E.P.M. & 66 & 42 & 0,102 & 95 & 35 & 0,069 \\
\hline
\end{tabular}

\begin{tabular}{|c|c|c|c|c|c|c|c|}
\hline Fonte de variação & GL & & & Vível de & încia $(\mathrm{P}<$ & & \\
\hline Bloco & 4 & 0,0001 & 0,0065 & 0,5798 & 0,0047 & 0,0434 & 0,1233 \\
\hline Tratamento & 3 & 0,0600 & 0,0068 & 0,3946 & 0,0911 & 0,0518 & 0,9734 \\
\hline Efeito linear & 1 & 0,1515 & 0,1041 & 0,3506 & 0,1839 & 0,0991 & 0,7320 \\
\hline Efeito quadrático & 1 & 0,0205 & 0,0422 & 0,5343 & 0,0975 & 0,0935 & 0,9386 \\
\hline Efeito cúbico & 1 & 0,0059 & 0,0052 & 0,1947 & 0,1120 & 0,0746 & 0,7699 \\
\hline $\mathrm{R}^{2}$ do modelo & & 0,9042 & 0,7865 & 0,3413 & 0,7427 & 0,6671 & 0,4354 \\
\hline Média & & 1797 & 760 & 2,381 & 2199 & 828 & 2,652 \\
\hline Desvio-padrão & & 147,4 & 93,8 & 0,229 & 213,1 & 77,7 & 0,154 \\
\hline Coeficiente de variação & & 8,20 & 12,35 & 9,62 & 9,69 & 9,38 & 5,82 \\
\hline
\end{tabular}

Médias na mesma coluna seguidas de mesma letra não diferem estatisticamente entre si pelo teste Tukey a $5 \%$ de probabilidade; ${ }^{*}$ ão-significativo.

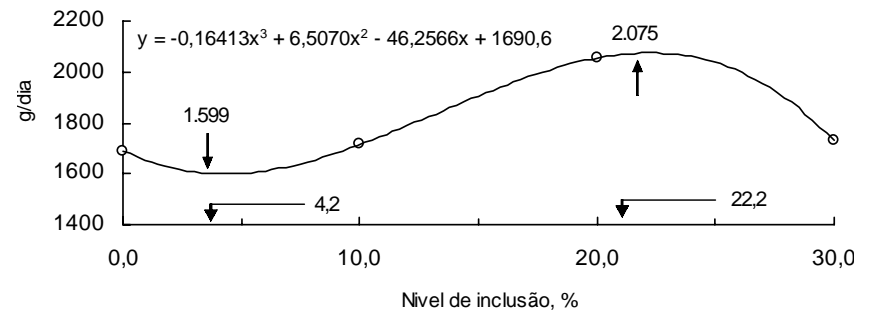

Figura 1 - Consumo de ração (g/dia) em suínos na fase de crescimento alimentados com rações contendo farelo de coco.

fase de crescimento, a redução no desempenho no nível superior a $20 \%$ de farelo de coco - uma vez neutralizado o efeito negativo do nível mais alto de farelo residual de milho nas dietas - pode estar relacionada ao efeito de substituição e à redução na concentração do farelo de soja na dieta com o nível de $30 \%$ de farelo de coco.

$\mathrm{Na}$ literatura são descritas muitas situações de uso de farelo de coco em substituição às fontes protéicas tendo como fontes de energia o milho ou os cereais de inverno. Grieve et al. (1966) estudaram o efeito da utilização de 10, 20 ou $30 \%$ de farelo de coco em rações para suínos em crescimento e terminação e concluíram que o ganho de peso e a conversão alimentar pioraram ligeiramente com a inclusão de farelo de coco na dieta. Creswell \& Brooks (1971b), em experimento com suínos alimentados com dietas contendo 0, 10, 20 ou 40\% de farelo de coco, observaram ganho de peso diário de 0,$76 ; 0,74 ; 0,65$ e 0,46 kg. Lekule et al. (1982) avaliaram dietas contendo $0,10,20$ ou $30 \%$ de farelo de coco até o peso de abate de $90 \mathrm{~kg}$ e observaram que a taxa e a

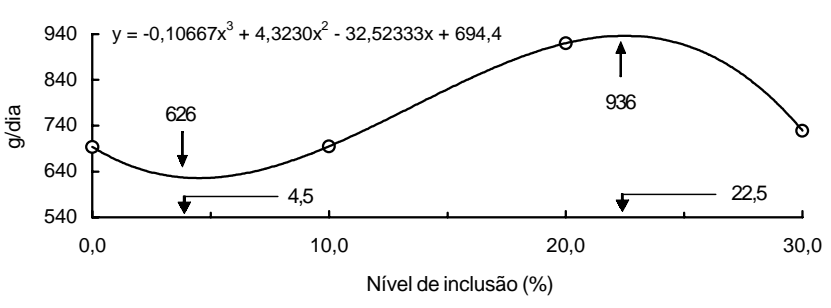

Figura 2 - Ganho de peso médio (g/dia) em suínos na fase de crescimento alimentados com rações contendo farelo de coco.

eficiência de ganho de peso reduziram com o fornecimento de níveis superiores a $10 \%$ de farelo de coco.

Neste experimento, o consumo de ração diminuiu quando o nível de farelo de coco ultrapassou $20 \%$, fato provavelmente decorrente da interação da fibra presente no farelo de coco e da proteína. Segundo Mitchell et al. (1945) e Woodroof (1970), o calor aplicado durante o processamento do farelo de coco pode tornar indisponível boa parte da lisina, reduzindo a qualidade da proteína e reduzindo o consumo. Creswell \& Brooks (1971a) também relataram que o uso de farelo de coco na alimentação de suínos é limitado, pois o balanço de aminoácidos essenciais é ruim e a qualidade da proteína do farelo de coco pode ser adversamente afetada durante o processamento. Mepba \& Achinewhu (2003) avaliaram o efeito do processamento sobre a qualidade nutritiva da proteína presente em farinha integral, farinha desengordurada e concentrado protéico de farinha integral de coco e obtiveram valores de digestibilidade da proteína que variaram de 88 a $94 \%$, indicando que, com adequado processamento, os 
coeficientes de digestibilidade da proteína presente no coco podem ser aumentados. Nesta pesquisa, somente LisinaHCL foi adicionada para obter o mesmo nível do aminoácido digestível em todas as dietas.

Kyriazakis \& Emmans (1995) relataram que, ao incluírem altos teores de fibra nas rações, pode ocorrer menor consumo de ração, como conseqüência do volume excessivo no trato intestinal ou da redução na palatabilidade. Segundo Kass et al. (1980a), níveis de fibra bruta de 7 a $10 \%$ na dieta têm efeito negativo sobre o desempenho de suínos em crescimento e a extensão desse efeito depende da fonte e do tipo de fibra. Neste estudo, o menor consumo ocorreu no nível reduzido de farelo de coco com altos níveis de farelo residual de milho e também no nível mais alto. Os teores de fibra bruta no farelo residual de milho e farelo de coco são 13,25 e 10,67\%. Embora os níveis de fibra detergente neutro sejam muito próximos, o valor de $21,58 \%$ de fibra detergente ácido (FDA) no farelo de coco é muito superior ao de 14,08\% presente no farelo residual de milho. O menor ganho de peso de animais alimentados com dietas fibrosas pode estar diretamente relacionado à diminuição simultânea do consumo de ração e da digestibilidade dos componentes nutritivos da ração, promovido pelo aumento do teor de fibra na dieta (Etienne, 1997). Schulze et al. (1994) observaram redução na digestibilidade ileal aparente e aumento na perda ileal de nitrogênio em suínos alimentados com rações com níveis crescentes de fibra detergente neutro.

$\mathrm{Na}$ fase de crescimento, a magnitude dos resultados da receita bruta média e do custo médio da alimentação refletiram os resultados do ganho de peso e consumo diários, respectivamente (Tabela 4). Dessa forma, o nível de $20 \%$ de farelo de coco na dieta promoveu aumento de $32,52 \%$ na receita bruta, de $17,45 \%$ no custo médio da alimentação e, como conseqüência, a margem bruta média foi $83,37 \%$ acima do valor observado com o uso da dieta-referência composta dos farelos residual de milho e de soja.

$\mathrm{Na}$ análise de regressão para ganho de peso e consumo, o efeito cúbico assumiu significância $(\mathrm{p}<0,05)$ e cada uma das equações (Tabela 5) apresentou dois níveis significantes de farelo de coco, correspondentes a um nível em que a estimativa para a variável-resposta assume valor mínimo e outro nível em que a estimativa para a variável-resposta assume valor máximo. Grieve et al. (1966), estudando o efeito da adição de 10, 20 e 30\% de farelo de coco em rações para suínos em crescimento e terminação, concluíram que a adição de $20 \%$ de farelo de coco proporcionou maior retorno de capital e diminuiu o custo da ração. O’Doherty \& McKeon (2000) realizaram dois experimentos com suínos nas fases de crescimento e terminação e concluíram que, quanto maior o nível de farelo de coco, menores os custos.

No período total, observou-se efeito significativo $(\mathrm{P}=0,0509)$ dos níveis de farelo de coco sobre a receita bruta média da ração. No nível de $20 \%$ de farelo de coco, o valor alcançado foi $19,42 \%$ acima do observado com o uso da dieta-referência, composta de farelo residual de milho e farelo de soja (Tabela 5).

A equação de regressão para a receita bruta média no período experimental indicou dois níveis de farelo de coco relevantes: um nível de 3,37\% de farelo de coco, no qual a receita bruta média estimada foi mínima, 137,90 R \$/suíno; e

Tabela 4 - Receita bruta média (RBM, R\$), custo médio da alimentação (CMA, R\$), margem bruta média (MBM, R\$) e rentabilidade média (RM, \%) da inclusão de farelo de coco nas dietas

\begin{tabular}{|c|c|c|c|c|c|c|c|c|c|}
\hline \multirow{2}{*}{\multicolumn{2}{|c|}{$\begin{array}{l}\text { Período experimental } \\
\text { Nível de farelo de coco }(\%)\end{array}$}} & \multicolumn{4}{|c|}{ Crescimento } & \multicolumn{4}{|c|}{ Crescimento-terminação } \\
\hline & & RBM & CMA & MBM & $\mathrm{RM}$ & $\mathrm{RBM}$ & CMA & MBM & $\mathrm{RM}$ \\
\hline \multicolumn{2}{|l|}{0} & $63,7 b$ & $49,2 b$ & $14,5 b$ & $30,0 \mathrm{~b}$ & $141,3 b$ & $115,6 b$ & $25,7 b$ & $23,6 \mathrm{a}$ \\
\hline \multicolumn{2}{|l|}{10} & $63,8 b$ & $49,0 \mathrm{~b}$ & $14,7 b$ & $31,2 b$ & $146,9 \mathrm{~b}$ & $118,2 b$ & $28,7 \mathrm{ab}$ & $25,1 \mathrm{a}$ \\
\hline \multicolumn{2}{|l|}{20} & $84,4 \mathrm{a}$ & $57,7 \mathrm{a}$ & $26,7 \mathrm{a}$ & $48,1 \mathrm{a}$ & $131,3 \mathrm{a}$ & $131,4 \mathrm{a}$ & $37,4 \mathrm{a}$ & $29,1 \mathrm{a}$ \\
\hline \multicolumn{2}{|l|}{30} & $66,9 b$ & $47,7 \mathrm{~b}$ & $19,3 b$ & $39,9 \mathrm{ab}$ & $115,1 \mathrm{~b}$ & $115,1 \mathrm{~b}$ & $36,0 \mathrm{a}$ & $31,2 \mathrm{a}$ \\
\hline \multicolumn{2}{|l|}{ EPM } & 3,85 & 1,96 & 3,04 & 6,23 & 6,37 & 5,19 & 3,88 & 3,38 \\
\hline Fonte de variação & GL & \multicolumn{8}{|c|}{ Nível de significância $(\mathrm{p}<\ldots \ldots . .)}$. \\
\hline Bloco & 4 & 0,0065 & 0,0001 & 0,9075 & 0,5422 & 0,0431 & 0,0039 & 0,5272 & 0,1139 \\
\hline Tratamento & 3 & 0,0067 & 0,0129 & 0,0497 & 0,1952 & 0,0509 & 0,1439 & 0,1533 & 0,3998 \\
\hline Efeito linear & 1 & 0,1029 & 0,6327 & 0,0792 & 0,1199 & 0,0974 & 0,6226 & 0,0422 & 0,1033 \\
\hline Efeito quadrático & 1 & 0,0419 & 0,0264 & 0,2348 & 0,4719 & 0,0927 & 0,0943 & 0,5813 & 0,9404 \\
\hline Efeito cúbico & 1 & 0,0051 & 0,0084 & 0,0408 & 0,1693 & 0,0740 & 0,1104 & 0,3830 & 0,7760 \\
\hline $\mathrm{R}^{2}$ & & 0,7870 & 0,8944 & 0,4887 & 0,4213 & 0,6679 & 0,7409 & 0,4459 & 0,5115 \\
\hline Média & & 69,71 & 50,91 & 18,81 & 37,29 & 151,99 & 120,04 & 31,95 & 27,26 \\
\hline Desvio-padrão & & 8,60 & 4,39 & 6,80 & 13,94 & 14,24 & 11,61 & 8,68 & 7,56 \\
\hline $\mathrm{CV}$ & & 12,34 & 8,61 & 36,14 & 37,37 & 9,37 & 9,67 & 27,17 & 27,75 \\
\hline
\end{tabular}

Médias na mesma coluna seguidas pela mesma letra não diferem entre si pelo teste de Tukey a $5 \%$ de probabilidade. *não-significativo. 
Tabela 5 - Receita bruta média (RBM, R\$/suíno), custo médio da alimentação (CMA, R\$/suíno) e margem bruta média (MBM, R\$/suíno) das rações

$\mathrm{Na}$ fase de crescimento

Receita bruta média

$\mathrm{RBM}=-0,0098 \mathrm{X}^{3}+0,3970 \mathrm{X}^{2}-2,9861 \mathrm{X}+63,7146$

$\mathrm{X}_{\text {min }}=4,52 \%, \mathrm{Y}_{\text {min }}=57,40 \mathrm{R} \$$ /suíno

$\mathrm{X}_{\text {max }}=22,5 \%, \mathrm{Y}_{\text {max }}=85,90 \mathrm{R} \$$ /suíno

Custo médio com a alimentação

$\mathrm{CMA}=-0,0046 \mathrm{X}^{3}+0,1824 \mathrm{X}^{2}-1,3772 \mathrm{X}+49,1619$

$\mathrm{X}_{\min }=0,38 \%, \mathrm{Y}_{\min }=49,14 \mathrm{R} \$ /$ suíno

$\mathrm{X}_{\text {max }}=26,1 \%, \mathrm{Y}_{\text {max }}=88,03 \mathrm{R} \$$ /suíno

Margem bruta média

$\mathrm{MBM}=-0,0052 \mathrm{X}^{3}+0,2146 \mathrm{X}^{2}-1,6089 \mathrm{X}+14,5527$

$\mathrm{X}_{\text {min }}=4,48 \%, \mathrm{Y}_{\min }=11,18 \mathrm{R} \$$ /suíno

$\mathrm{X}_{\text {max }}=23,1 \%, \mathrm{Y}_{\text {max }}=27,92 \mathrm{R} \$$ suíno

$\mathrm{Na}$ fase de crescimento e terminação

Receita bruta média

$\mathrm{RBM}=-0,0093 \mathrm{X}^{3}+0,3599 \mathrm{X}^{2}-2,1098 \mathrm{X}+141,2786$
$\mathrm{X}_{\min }=3,4 \%, \mathrm{Y}_{\min }=137,90 \mathrm{R} \$$ /suíno
$\mathrm{X}_{\max }=22,4 \%, \mathrm{Y}_{\max }=170,08 \mathrm{R}$ /suíno

outro de $22,43 \%$ de farelo de coco no qual a receita bruta média estimada foi máxima, 170,08 R \$/suíno.

\section{Conclusões}

Para suínos na fase de crescimento e no período total, o nível de farelo de coco recomendado para dietas compostas de farelo residual de milho e farelo de soja é de $22,5 \%$ porque promove melhor desempenho e maior retorno econômico.

\section{Literatura Citada}

ANDERSON, C.; LINDBERG, J.E. Forages in diets for growing pigs. 2. Nutrient apparent digestibilities and partition of nutrient digestion in barley-based diet including red-clover and perennial rye grass meal. Animal Science, v.65, n.3, p.493-500, 1997.

ANDRADE, A.N. Produção mundial de grãos e a situação atual e perspectivas do milho e soja no mercado brasileiro. In: SIMPÓSIO SOBRE INGREDIENTES NA ALIMENTAÇÃO ANIMAL, 1., 2001, Campinas. Anais... Campinas: Instituto de Tecnologia de Alimentos, 2001. p.1-32

CRESWELl, D.C.; BROOKS, C.C. Composition, apparent digestibility and energy evaluation of coconut oil and coconut meal. Journal of Animal Science, v.33, n.2, p.366-369, 1971a.

CRESWELL, D.C.; BROOKS, C.C. Effect of coconut meal on coturnix quail and of coconut meal and coconut oil on performance, carcass measurements and fat composition in swine. Journal of Animal Science, v.33, n.2, p.370-5, 1971 b.

ETIENNE, M. Utilization of high fibre and cereal by sow. A review. Livestock Production Science, v.16, p.229-251, 1997.
FIALHO, E.T.; BARBOSA, H.P.; ALBINO, L.F. Análise proximal e determinação dos valores energéticos de alguns alimentos para suínos. In: REUNIÃO ANUAL DA SOCIEDADE BRASILEIRA DE ZOOTECNIA, 22., 1985, Camboriú. Anais... Camboriú: Sociedade Brasileira de Zootecnia, 1985. p.243.

FUNDAÇÃO INSTITUTO BRASILEIRO DE GEOGRAFIA E ESTATÍSTICA - FIBGE. [2004]. Estatística de área cultivada. Disponível em: <http://www.ibge.gov.br> Acesso em: 6/6/2006

GRIEVE, L.M.; OSBOURN, D.F.; GONZALES, F.O. Coconut oil meal in growing and finishing rations for swine. Tropical Agriculture, v.43, n.3, p.257-61, 1966.

HONG, J.W.; KIM, I.H.; HAN, Y.K. et al. Energy of various soybean meal, rapeseed meal and coconut meal in finishing pigs. Journal of Animal Science, v.80, suppl. 1, 2003 (abstract, 891).

KASS, M.L.; van SOEST, P.J.; POND, W.G. Utilization of dietary fiber from alfalfa by growing swine. I. Apparent digestibility of diet components in specific segments of the gastrointestinal tract. Journal of Animal Science, v.50, n.1, p.175-191, $1980 \mathrm{a}$

KASS, M.L.; van SOEST, P.J.; POND, W.G. et al. Utilization of dietary fiber from alfalfa by growing swine. II. Volatile fatty acid concentration in and disappearance from the gastrointestinal tract. Journal of Animal Science, v.50, n.1, p.192-197, 1980b.

KYRIAZAKIS, I.; EMMANS, G.C. The voluntary feed intake of pigs given feeds based on wheat bran, dried citrus pulp and grass meal, in relation to measurements of feed bulk. British Journal of Nutrition, v.73, n.1, p.191-297, 1995.

LANNA, G.R.Q. Avicultura. Recife: Universidade Federal Rural de Pernambuco, 2000. p.241-244

LEKULE, F.P.; HOMB, T.; KATAGILE, J.A. Optimum inclusion of coconut meal in growing-finishing pig diets. East African Agricultural and Forestry Journal, v.48, n.1, p.19-24, 1982.

MEPBA, H.D.; ACHINEWHU, S.C. Effects of processing on protein nutritive quality of cocconut Cocos nucifera products. Plant Foods for Human Nutrition, v.58, n.1, p.15-25, 2003.

MITCHELL, H.H.; HAMILTON, T.S.; BEADLES, J.R. The importance of commercial processing for the protein value of food products. Journal of Nutrition, v.29, n.1, p.13-25, 1945

NOBLET, J.; PEREZ, J.M. Prediction of digestibility of nutrients and energy values of pig diets from chemical analysis. Journal of Animal Science, v.71, n.12, p.3389-3198, 1993

NOVUS. Raw material compendium. Brussels: Novus International, 1994. p.327.

O'DOHERTY, J.V.; MCKEON, M.P. The use of expeller copra meal in grower and finisher pig diets. Livestock Production Science, v.67, n.1, p.55-65, 2000

ROSTAGNO, H.S.; ALBINO, L.F.T.; DONZELE, J.L. et al Tabelas brasileiras para aves e suínos: composição de alimentos e exigências nutricionais. Viçosa, MG: Universidade Federal de Viçosa, 2000. 141p.

ROSTAGNO, H.S.; ALBINO, L.F.T.; DONZELE, J.L. et al Tabelas brasileiras para aves e suínos: composição de alimentos e exigências nutricionais. 2.ed. Viçosa, MG: Universidade Federal de Viçosa, 2005. 186p.

SCHULZE, H.; van LEEUWEN, P.; VERSTEGEN, M.V.A. et al Effect of level of dietary neutral detergent fiber on ileal apparent digestibility and ileal nitrogen losses in pigs. Journal of Animal Sciences, v.72, n. 8, p.2362-2368, 1994

SILVA, J.B. Farelo residual de milho (Hominy Feed) na alimentação de suínos nas fases inicial e crescimento. Fortaleza: Universidade Federal do Ceará, 1996. 113p. Dissertação (Mestrado em Zootecnia) - Universidade Federal do Ceará, 1996.

STATISTICAL ANALYSES SYSTEM - SAS. SAS users' guide: statistics. Version 8. Cary: 1999. (CD-ROM).

WOODROOF, J.G. Coconuts production, processing, products Wesport: AVI Publication, 1970. p.43-72. 